Gut and Liver, Vol. 10, No. 5, September 2016, pp. 836-841

\title{
MicroRNA 141 Expression Is a Potential Prognostic Marker of Biliary Tract Cancers
}

\author{
Jaihwan Kim, Ji Kon Ryu, Sang Hyub Lee, and Yong-Tae Kim \\ Department of Internal Medicine and Liver Research Institute, Seoul National University College of Medicine, Seoul, Korea
}

\section{See editorial on page 663.}

Background/Aims: In recent years, a large number of microribonucleic acids (miRNAs) have been identified as putative prognostic biomarkers for solid cancers because of their role in controlling the expression of oncogenes and tumor suppressor genes. The aim of this study was to verify the utility of miRNA 141 as a prognostic biomarker of biliary tract cancers. Methods: From June 2010 to June 2012, common bile duct cancer tissue samples and matched noncancerous tissues from the ampulla of Vater were obtained from patients with biliary tract cancer undergoing endoscopic retrograde cholangiopancreatography. Using quantitative real-time polymerase chain reaction assays, we measured the mean relative expression levels of miRNA 141 in both groups of tissues. Overexpression of miRNA 141 was defined as a greater than 2 -fold increase in expression levels as determined by the $2^{-\Delta \Delta \mathrm{ct}}$ method. Results: In a cohort of 38 patients with biliary tract cancers (seven gallbladder, 13 hilar, and 18 distal bile duct cancers), 26 patients (68.4\%) were male, and the median age was 69.5 (52 to 85) years. Nineteen patients (50\%) had undergone $\mathrm{RO}$ resection procedures, including three Whipple operations, seven pylorus-preserving pancreaticoduodenectomies, six bile duct resections, and three extended lobectomies. Among the patients who had undergone RO resection, the overexpression of miRNA 141 was significantly associated with shorter disease-free survival and a greater risk of angiolymphatic invasion. Among the patients who did not undergo RO resection, miRNA 141 overexpression was significantly associated with reduced overall survival. Conclusions: Overexpression of miRNA 141 is an indicator of a poor prognosis in patients with biliary tract cancer, suggesting that
miRNA 141 may be a valuable prognostic biomarker of this disease. (Gut Liver 2016;10:836-841)

Key Words: Biliary tract neoplasms; MicroRNAs; Prognosis; Biomarkers

\section{INTRODUCTION}

In 2013, biliary tract cancers are the sixth leading cause of cancer associated deaths in Korea. ${ }^{1}$ To improve the outcomes of these diseases, diagnosis of early stage cancer, identification of risk factor for recurrence, and effective adjuvant chemotherapy are necessary. As part of these efforts, there have been many studies about the new biomarker for early diagnosis and predicting recurrence. However, there is no widely accepted biomarker except carbohydrogen antigen 19-9 (CA 19-9), yet. ${ }^{2}$

A micro-ribonucleic acid (miRNA) is a small noncoding RNA which contains 10 to 24 nucleotides. ${ }^{3}$ It has important functions such as posttranscriptional regulation of gene expression and silencing in normal cells. Compared to normal cells, many miRNAs are involved and recognized as new biomarkers in gastrointestinal solid malignancies such as pancreatic, esophageal, and hepatocellular cancers. ${ }^{4-6}$ However, there were limited studies about miRNA in biliary tract cancers although there was a report that miRNA 141 was highly overexpressed in malignant cholangiocytes and appeared to be a regulator of tumor cell proliferation in vitro. $^{7}$

Based on this background, we aimed to identify the clinical role of miRNA 141 which was from the biopsy samples during endoscopic retrograde cholangiopancreatography in patients with extrahepatic biliary tract cancers such as perihilar bile duct, distal common bile duct, and gallbladder cancer.

\footnotetext{
Correspondence to: Ji Kon Ryu

Department of Internal Medicine and Liver Research Institute, Seoul National University Hospital, Seoul National University College of Medicine, 101 Daehak-ro, Jongno-gu, Seoul 03080, Korea

Tel: +82-2-2072-1962, Fax: +82-2-762-9662, E-mail: jkryu@snu.ac.kr

Received on September 9, 2015. Revised on November 13, 2015. Accepted on December 11, 2015. Published online May 16, 2016 pISSN 1976-2283 eISSN 2005-1212 http://dx.doi.org/10.5009/gnl15460

@ This is an Open Access article distributed under the terms of the Creative Commons Attribution Non-Commercial License (http://creativecommons.org/licenses/by-nc/4.0) which permits unrestricted non-commercial use, distribution, and reproduction in any medium, provided the original work is properly cited.
} 


\section{MATERIALS AND METHODS}

\section{Patients}

From June 2010 to December 2012, a total of 38 patients with biliary tract cancers were enrolled in Seoul National University Hospital. They underwent endoscopic retrograde cholangiopancreatography (ERCP) for tissue acquisition and biliary drainage. Their medical records and radiological findings were reviewed.

\section{Tissue acquisition and miRNA extraction}

Cancer samples were acquired in the common bile duct after cannulation and acquisition of cholangiogram. For the purpose of acquisition of normal sample, endoscopic biopsy in ampulla of Vater was performed after sphincterotomy in the same patient. Tissue samples were stored in a deep freezer at $-70^{\circ} \mathrm{C}$. For miRNA extraction, frozen tissue was melted at $4^{\circ} \mathrm{C}$. Using a mirVANA ${ }^{\mathrm{TM}}$ miRNA isolation kit $\left(\right.$ Ambion $^{\circledR}$; Life Technologies Korea, Seoul, Korea), extraction was done according to the manufacturer's protocol.

\section{3. miRNA quantitative reverse transcription-polymerase chain reaction analysis}

Quantitative reverse transcription (qRT)-polymerase chain reaction (PCR) was used to detect the miRNA level in samples. Quantitative analysis of miRNA of tissue samples were performed using predesigned TaqMan ${ }^{\circledR}$ miRNA assays (Applied Biosystems, Foster City, CA, USA). The miRNA assays are a 2-step process. Using a miRNA 141 specific RT-PCR primer, complementary deoxyribonucleic acid (cDNA) was prepared. Then, RT-PCR was followed with TaqMan ${ }^{\circledR}$ probes. The noncoding RNU6B (U6 control) was used as housekeeping control. These assays target the mature miRNA 141 sequences, only.

\section{Analysis of the quantitative RT-PCR results}

The expression of each miRNA relative to U6 RNA is determined using qRT-PCR results which are expressed as mean relative fold change of expression. It is also known as the $2^{-\Delta \Delta \mathrm{Ct}}$ method. ${ }^{8}$ In this method, $\Delta \Delta \mathrm{Ct}$ was as follows:

$\Delta \Delta \mathrm{Ct}=\frac{\text { [miRNA } 141 \text { of cancer tissue-U6 RNA of cancer tissue] }}{\text { [miRNA } 141 \text { of normal mucosa-U6 RNA of normal mucosa] }}$

In this study, overexpression of miRNA 141 is defined as more than 2-fold change of expression.

\section{Statistics}

Statistical analysis was done with statistical software PASW version 18.0 for Windows (SPSS Inc., Chicago, IL, USA). Categorical variables were compared with the chi-square test or Fisher exact test. Comparison of continuous variables was done with the Mann-Whitney U test. The Kaplan-Meier analysis was used to generate survival curves and calculate median survival time. Disease-free survival and overall survival according to each of the evaluated clinical characteristics was compared by log-rank test. Two-sided p-values less than 0.05 were considered statistically significant.

\section{Ethics statement}

The study was approved by the Institutional Review Board of Seoul National University Hospital (IRB number: H-1007-067323). Informed consent was waived by the IRB.

\section{RESULTS}

\section{Overall characteristics of patients}

A total of 38 patients were enrolled in this study (Table 1). Twenty-six (68.4\%) were male and the median age was 69.5 years. Nineteen patients underwent R0 resection, two underwent palliative surgery (one bypass surgery and one simple cholecystectomy), and others did not undergo surgery. According to location of cancer, 13 had perihilar bile duct cancer, 18 had common bile duct, and seven had gallbladder cancer. There was no gallbladder cancer patient who underwent Ro resection. Fifteen patients (39.5\%) were diagnosed as stage IV and four patients $(10.5 \%)$ who had resectable stage cancer did not undergo R0 resection because of comorbidities or patients' refusal. As for the R0 resection, 10 underwent pancreaticoduodenectomies including three Whipple's operations and seven pylorus preserving pancreaticoduodenectomies. Six patients underwent bile duct resection and three underwent extended hepatic lobectomy. There was significant difference of median overall survival between patients with and without R0 resection (147.3 weeks vs 31.4 weeks, $\mathrm{p}<0.001)$. Median $2^{-\Delta \Delta \mathrm{ct}}$ result of miRNA 141 was 0.67 and there was no difference between the patients who had undergone R0 resection and those who had not.

\section{2. miRNA 141 in patients with R0 surgical resection}

In patients with R0 surgical resection, there were four and 15 patients with and without overexpression of miRNA 141. Although there was no difference of other clinical factors between two groups, angiolymphatic invasion is significantly more frequent in patients with overexpression than those without overexpression (Table 2). There was no difference in overall survival between patients with and without overexpression (median, 167.5 weeks vs undefined, $p=0.573$ ) (Fig. 1); however, there was a significant difference of disease free survival between two groups (median, 66.2 weeks vs undefined, $\mathrm{p}=0.039$ ) (Fig. 2).

\section{3. miRNA 141 in patients without RO surgical resection}

In patients without R0 surgical resection, there were three and 16 patients with and without overexpression of miRNA 141 (Table 3). Compared to the patients with R0 surgical resection, patients who did not undergo Ro surgical resection without overexpression of miRNA 141 was significantly associated with better overall survival than those with overexpression (51.0 weeks vs 3.1 weeks, p<0.001) (Fig. 3). 
Table 1. Overall Characteristics of Patients

\begin{tabular}{|c|c|c|c|c|}
\hline Characteristic & $\begin{array}{l}\text { With R0 resection } \\
\qquad(n=19)\end{array}$ & $\begin{array}{l}\text { Without R0 resection } \\
\qquad(\mathrm{n}=19)\end{array}$ & $\begin{array}{c}\text { Total } \\
(n=38)\end{array}$ & p-value \\
\hline Male sex & $16(84.2)$ & $10(52.6)$ & $26(68.4)$ & 0.036 \\
\hline Age, yr & $71(52-85)$ & $69(54-85)$ & $69.5(52-85)$ & 0.549 \\
\hline Location of cancer & & & & 0.013 \\
\hline Perihilar bile duct & 7 (36.8) & $6(31.6)$ & $13(34.2)$ & \\
\hline Distal bile duct & $12(63.2)$ & $6(31.6)$ & $18(47.4)$ & \\
\hline Gallbladder & 0 & 7 (36.8) & 7 (18.4) & \\
\hline Stage & & & & - \\
\hline I & $2(10.5)$ & $2(10.5)$ & $4(10.5)$ & \\
\hline II & $14(73.7)$ & 0 & $14(36.8)$ & \\
\hline III & $3(15.8)$ & $2(10.5)$ & $5(13.2)$ & \\
\hline IV & 0 & 15 (78.9) & $15(39.5)$ & \\
\hline Operation & & & & - \\
\hline Whipple & 3 & - & 3 & \\
\hline PPPD & 7 & - & 7 & \\
\hline Bile duct resection & 6 & - & 6 & \\
\hline Extended lobectomy & 3 & - & 3 & \\
\hline Bypass surgery & - & 1 & 1 & \\
\hline Cholecystectomy & - & 1 & 1 & \\
\hline No operation & - & 17 & 17 & \\
\hline Median $2^{-\Delta \Delta C t}$ level of miRNA 141 & $0.60(0.04-4.48)$ & $0.80(0.00-48.89)$ & $0.67(0.00-48.89)$ & 0.907 \\
\hline No. of patients with miRNA 141 overexpression & $4(21.1)$ & $3(15.8)$ & $7(18.4)$ & $>0.99$ \\
\hline
\end{tabular}

Data are presented as number (\%) or median (range).

PPPD, pylorus-preserving pancreaticoduodenectomy; miRNA, micro-ribonucleic acid.

Table 2. Characteristics of Patients Who Had Undergone Ro Surgical Resection

\begin{tabular}{|c|c|c|c|c|}
\hline Characteristic & $\begin{array}{l}\text { Without overexpression of } \\
\text { miRNA } 141(n=15)\end{array}$ & $\begin{array}{l}\text { With overexpression of } \\
\text { miRNA } 141(n=4)\end{array}$ & Total $(n=19)$ & p-value \\
\hline Male sex & $12(80.0)$ & $4(100.0)$ & $16(84.2)$ & $>0.99$ \\
\hline Age, yr & $71(52-78)$ & $66(55-85)$ & $71(52-85)$ & 0.993 \\
\hline Malignancy & & & & 0.603 \\
\hline Perihilar & 5 (33.3) & $2(50.0)$ & $7(36.8)$ & \\
\hline Distal & $10(66.7)$ & $2(50.0)$ & $12(63.2)$ & \\
\hline Stage & & & & $>0.99$ \\
\hline I & 2 (13.3) & 0 & $2(10.5)$ & \\
\hline II & $11(73.3)$ & $3(75.0)$ & $14(73.7)$ & \\
\hline III & $2(13.3)$ & $1(25.0)$ & $3(15.8)$ & \\
\hline Differentiation & & & & $>0.99$ \\
\hline Well & $3(20.0)$ & 0 & $3(15.8)$ & \\
\hline Moderately & $8(53.3)$ & $3(75.0)$ & $11(57.9)$ & \\
\hline Poorly & 4 (26.7) & $1(25.0)$ & $5(26.3)$ & \\
\hline \multicolumn{5}{|l|}{ Invasion } \\
\hline Angiolymphatic & $3(20.0)$ & $4(100.0)$ & $7(36.8)$ & 0.009 \\
\hline Venous & $1(6.7)$ & $1(25.0)$ & $2(10.5)$ & 0.386 \\
\hline Perineural & 13 (86.7) & $4(100.0)$ & 17 (89.5) & $>0.99$ \\
\hline
\end{tabular}

Data are presented as number (\%) or median (range). miRNA, micro-ribonucleic acid. 


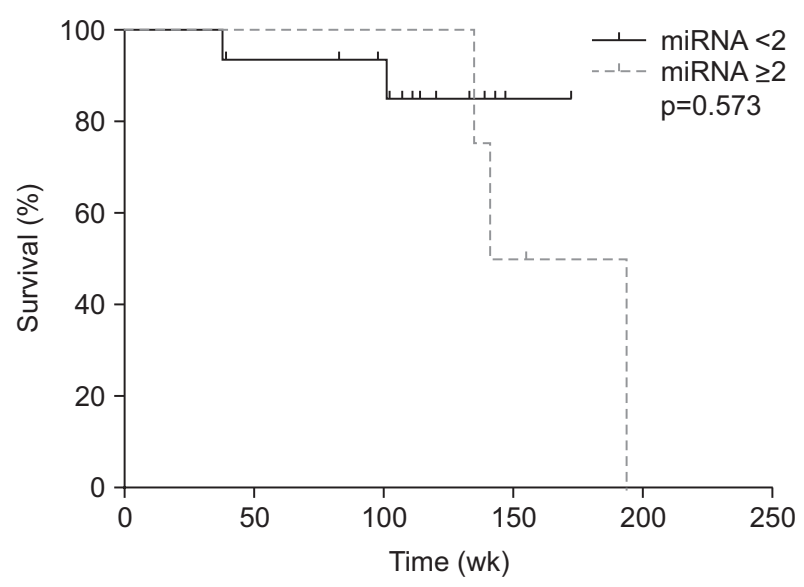

Fig. 1. Kaplan-Meier curves revealed that in patients who had undergone R0 resection there was no significant difference in overall survival associated with miRNA 141 overexpression. miRNA, micro-ribonucleic acid.

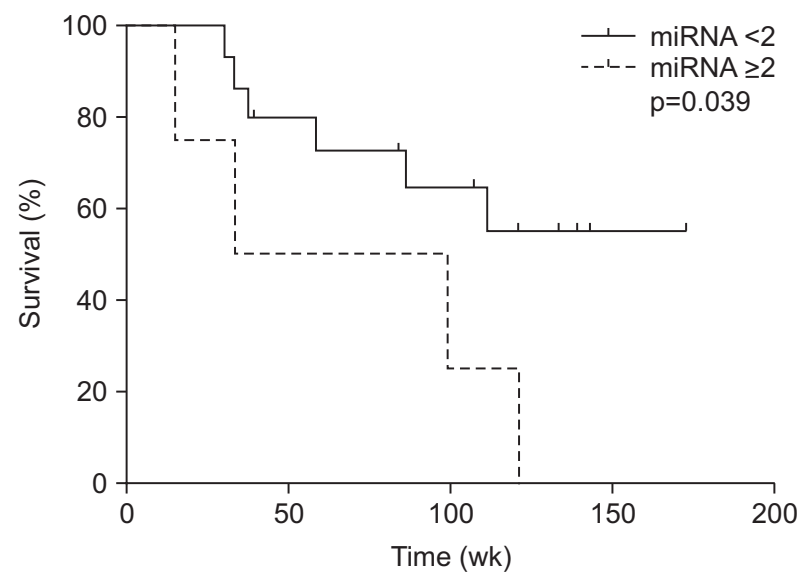

Fig. 2. Kaplan-Meier curves revealed a significant difference in the disease-free survival of patients who had undergone R0 resection with and without overexpression of miRNA 141.

miRNA, micro-ribonucleic acid.
Ten patients without overexpression of miRNA 141 received palliative chemotherapy; however, there was no one who received it in patients with overexpression. Palliative chemotherapy regimens were as follows: gemcitabine with cisplatin (four), gemcitabine with TS-1 (four), gemcitabine only (one), and cisplatin with TS-1 (one).

Although patients without overexpression of miRNA 141 were associated with palliative chemotherapy with borderline significance, palliative chemotherapy was not significantly associated with overall survival period.

\section{DISCUSSION}

Because the 5-year survival of biliary tract cancers is variable according to their origin, the exact prognosis using clinicopathological information is very limited. ${ }^{9}$ Furthermore, few

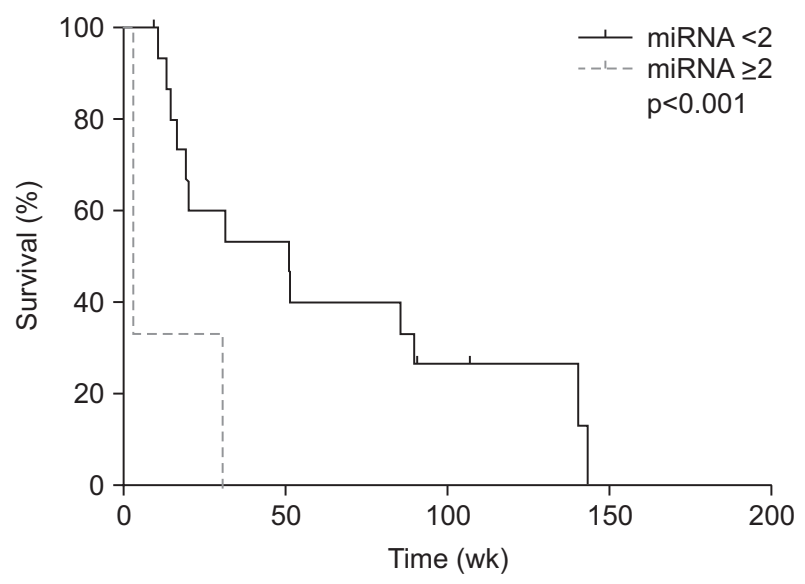

Fig. 3. Kaplan-Meier curves revealed that a significant difference in overall survival was associated with miRNA 141 overexpression in patients who had not undergone R0 resection. miRNA, micro-ribonucleic acid.

Table 3. Characteristics of Patients Who Had Not Undergone Ro Surgical Resection

\begin{tabular}{|c|c|c|c|c|}
\hline Characteristic & $\begin{array}{l}\text { Without overexpression of } \\
\text { miRNA } 141(\mathrm{n}=16)\end{array}$ & $\begin{array}{l}\text { With overexpression of } \\
\text { miRNA } 141(\mathrm{n}=3)\end{array}$ & Total $(n=19)$ & p-value \\
\hline Male sex & $7(43.8)$ & $3(100.0)$ & $10(52.6)$ & 0.211 \\
\hline Age, yr & $69(54-85)$ & $77(69-82)$ & $69(54-85)$ & 0.145 \\
\hline Malignancy & & & & $>0.99$ \\
\hline Perihilar & $5(31.3)$ & $1(33.3)$ & $6(31.6)$ & \\
\hline Distal & $5(31.3)$ & $1(33.3)$ & $6(31.6)$ & \\
\hline Gallbladder & $6(37.5)$ & $1(33.3)$ & $7(36.8)$ & \\
\hline Stage & & & & $>0.99$ \\
\hline I & $2(12.5)$ & 0 & $2(10.5)$ & \\
\hline III & $2(12.5)$ & 0 & $2(10.5)$ & \\
\hline IV & $12(75.0)$ & $3(100.0)$ & 15 (78.9) & \\
\hline Palliative chemotherapy & $10(66.7)$ & 0 & $10(55.6)$ & 0.069 \\
\hline
\end{tabular}

Data are presented as number (\%) or median (range). miRNA, micro-ribonucleic acid. 
biomarkers except CA 19-9 are known in biliary tract cancer. ${ }^{2}$ miRNAs which are small noncoding RNAs have been suggested as biomarkers in gastrointestinal solid malignancies including esophageal cancer, pancreatic cancer, and liver cancer. ${ }^{4-6}$ In that aspect, miRNAs could be candidate prognostic biomarkers in biliary tract cancer although there are still limited data. ${ }^{10-12}$

miRNA 141 is a member of the miRNA 200 family. miRNA 141 was chosen in current study because of a previous study which reported that miRNA 141 was highly overexpressed in malignant cholangiocytes compared to nonmalignant cholangiocytes. ${ }^{7}$ In addition, this study suggested that miRNA 141 appears to be an important regulator of tumor cell proliferation in vitro and the strategies to decrease miRNA 141 overexpression may be potentially useful to limit tumor growth. Although there was another study that miRNA $200 \mathrm{~b} / \mathrm{c}$ which is another member of miRNA 200 family, could regulate the migration and invasion capacity of cholangiocarcinoma cell lines and tumorigenic properties, ${ }^{13}$ we tried to assess the role of miRNA 141 as a biomarker from this background.

In this study, the prognosis of patients with R0 resection was much better than that of patients without surgery. However, there was no significant difference of median expression levels of miRNA 141 although it was insignificantly lower in patients with R0 resection than those without R0 resection (0.60 vs 0.80 , $\mathrm{p}=0.907)$.

Among the patients with R0 resection, the overexpression of miRNA 141 was significantly associated with angiolymphatic invasion in the surgical specimens. Considering that angiolymphatic invasion is regarded as a negative prognostic factor in other cancers, ${ }^{14,15}$ our results implicates that the overexpression of miRNA 141 might be associated with worse clinical outcomes. It is also supported by that disease free survival of patients with overexpression of miRNA 141 was significantly shorter than those without overexpression although there was no difference of overall survival.

Among the patients without R0 resection, there was a significant difference of overall survival between the patients with and without overexpression. Although more patients without overexpression of miRNA 141 received palliative chemotherapy than those with overexpression, palliative chemotherapy was not statistically significant factor for overall survival. As a result, overexpression of miRNA 141 was the only clinical factor which is significantly associated with overall survival.

In this study, there are three limitations. First, there are patients with extrahepatic bile duct cancer or gallbladder cancer which are of different staging system, surgical treatments, and prognosis. Because of such heterogeneous composition of patients, it is difficult to draw a universal principle although both bile duct and gallbladder cancer are usually regarded as a biliary tract cancer. Second, we could not know the exact number of samples which contain cancer tissue because ERCP-guided endobiliary biopsy for the bile duct has 70\% to $80 \%$ sensitiv- ity for diagnosing biliary malignancies. Finally, the results of this study are based on miRNA results only. For the concrete evidence, further studies with protein, animal, and humans are necessary.

In conclusion, overexpression of miRNA 141 is associated with poor prognostic indicators in patients with biliary tract cancer and shows a possibility as a prognostic biomarker in these patients. Further studies are necessary to confirm it.

\section{CONFLICTS OF INTEREST}

No potential conflict of interest relevant to this article was reported.

\section{ACKNOWLEDGEMENTS}

This study was supported by the Seoul National University Hospital Research Fund (grant number: 03-2010-0130).

\section{REFERENCES}

1. National Cancer Information Center. Cancer information services [Internet]. Goyang: National Cancer Information Center; c2016 [cited 2016 Mar 12]. Available from: http://www.cancer.go.kr/ mbs/cancer.

2. Grunnet M, Mau-Sørensen M. Serum tumor markers in bile duct cancer: a review. Biomarkers 2014;19:437-443.

3. Croce CM. Causes and consequences of microRNA dysregulation in cancer. Nat Rev Genet 2009;10:704-714.

4. Halkova T, Cuperkova R, Minarik M, Benesova L. MicroRNAs in pancreatic cancer: involvement in carcinogenesis and potential use for diagnosis and prognosis. Gastroenterol Res Pract 2015;2015:892903.

5. Sakai NS, Samia-Aly E, Barbera M, Fitzgerald RC. A review of the current understanding and clinical utility of miRNAs in esophageal cancer. Semin Cancer Biol 2013;23(6 Pt B):512-521.

6. Lyra-González I, Flores-Fong LE, González-García I, MedinaPreciado D, Armendáriz-Borunda J. MicroRNAs dysregulation in hepatocellular carcinoma: insights in genomic medicine. World J Hepatol 2015;7:1530-1540.

7. Meng F, Henson R, Lang M, et al. Involvement of human microRNA in growth and response to chemotherapy in human cholangiocarcinoma cell lines. Gastroenterology 2006;130:2113-2129.

8. Schmittgen TD, Jiang J, Liu Q, Yang L. A high-throughput method to monitor the expression of microRNA precursors. Nucleic Acids Res 2004;32:e43.

9. Blechacz B, Komuta M, Roskams T, Gores GJ. Clinical diagnosis and staging of cholangiocarcinoma. Nat Rev Gastroenterol Hepatol 2011;8:512-522.

10. Zhang J, Han C, Wu T. MicroRNA-26a promotes cholangiocarcinoma growth by activating beta-catenin. Gastroenterology 2012;143:246-256.e8. 
11. Meng F, Wehbe-Janek H, Henson R, Smith H, Patel T. Epigenetic regulation of microRNA-370 by interleukin- 6 in malignant human cholangiocytes. Oncogene 2008;27:378-386.

12. Mott JL, Kobayashi S, Bronk SF, Gores GJ. mir-29 regulates Mcl-1 protein expression and apoptosis. Oncogene 2007;26:6133-6140.

13. Peng F, Jiang J, Yu Y, et al. Direct targeting of SUZ12/ROCK2 by $\mathrm{miR}-200 \mathrm{~b} / \mathrm{c}$ inhibits cholangiocarcinoma tumourigenesis and metastasis. Br J Cancer 2013;109:3092-3104.
14. Knijn N, de Ridder JA, Punt CJ, de Wilt JH, Nagtegaal ID. Histopathological evaluation of resected colorectal cancer liver metastases: what should be done? Histopathology 2013;63:149-156.

15. Wu CF, Wu CY, Fu JY, et al. Prognostic value of metastatic N1 lymph node ratio and angiolymphatic invasion in patients with pathologic stage IIA non-small cell lung cancer. Medicine (Baltimore) 2014;93:e102. 